\title{
A Case of Retropharyngeal Abscess Resulting from Infected Paratracheal Cyst
}

\author{
Eun Soo Lee ${ }^{1}$, Heon Soo Park ${ }^{1}$, Sang Hyeon Kim², and Dong Kun Lee ${ }^{1} \mathbb{D}$ \\ ${ }^{1}$ Departments of Otorhinolaryngology-Head and Neck Surgery, ${ }^{2}$ Radiology, College of Medicine, Dong-A University, Busan, Korea
}

\author{
감염된 기관 낭종에서 기인한 후인두 농양 1 예 \\ 이은수 ${ }^{1} \cdot$ 박헌수 $^{1} \cdot$ 김상현 $^{2} \cdot$ 이동근 ${ }^{1}$ \\ 동아대학교 의과대학 이비인후-두경부외과학교실, ${ }^{1}$ 영상의학교실 ${ }^{2}$
}

\author{
Received July 22, 2019 \\ Revised September 30, 2019 \\ Accepted October 29, 2019 \\ Address for correspondence \\ Dong Kun Lee, MD, PhD \\ Department of Otorhinolaryngology- \\ Head and Neck Surgery, \\ College of Medicine, \\ Dong-A University, \\ 26 Daesingongwon-ro, Seo-gu, \\ Busan 49201, Korea \\ Tel $+82-51-240-5428$ \\ Fax $+82-51-253-0712$ \\ E-mail chaos001@hanmail.net
}

\begin{abstract}
A paratracheal cyst is an air-filled cyst lined by a ciliated epithelium, commonly referred to as a tracheal diverticulum. The most common location of paratracheal cysts is the right side of posterolateral tracheal wall. It occurs in $0.3 \%$ to $8.1 \%$ of the total population. Most paratracheal cysts are asymptomatic and discovered incidentally on routine radiologic examination. Rarely, however, symptoms such as cough or fever are encountered and chronic infection of the paratracheal cyst usually present itself like a tucoberculosis or a tumor. There are few case reports of deep neck infection caused by a paratracheal cyst. We report a case of retropharyngeal abscess resulting from an infected paratracheal cyst.
\end{abstract}

Korean J Otorhinolaryngol-Head Neck Surg 2020;63(3):134-7

Key Words Bronchogenic cyst · Head and Neck Neoplasms · Infection · Neck.

\section{서 론}

기관 낭종은 섬모성 상피로 덮여 있는 공기가 가득 찬 낭 종이며, 통상적으로 기관 게실로 알려져 있다. 기관에서 드물 게 발생하며 주로 식도가 지나가지 않는 우측에서 호발한다.) 전체 인구의 $0.78 \sim 8.1 \%$ 정도 발생한다고 알려져 있다. 드물게 기침이나 발열 등의 증상이 나타나지만, 대다수의 기관 낭종 은 증상 없이 영상 검사에서 우연히 발견된다. ${ }^{2)}$ 기관 낭종의 만성 감염은 주로 결핵이나, 종양처럼 나타나게 되며, 심경부 감염이 동반되어 보이는 예는 드물며, 국내에서는 단 1 예가 보고되어 있다. ${ }^{3)}$ 저자들은 감염된 기관 낭종에서 기인한 후 인두 농양을 진단 및 치료하여 문헌 고찰과 함께 보고하는 바이다.

This is an Open Access article distributed under the terms of the Creative Commons Attribution Non-Commercial License (https://creativecommons.org/licenses/by-nc/4.0) which permits unrestricted non-commercial use, distribution, and reproduction in any medium, provided the original work is properly cited.

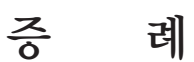

49세 남자 환자가 3일 전부터 시작된 인후통, 발열 등으로 타 병원을 방문하였으며, 목 초음파 검사에서 우측 후인두 부 위의 심경부 감염이 의심되어 본원으로 내원하였다. 과거력 상 당뇨 이외에는 특이 소견 없었고, 외상이나 최근 치과 질 환의 병력도 없었다. 신체 검사에서는 우측 쇄골 윗부분에 압 통을 호소하였으며, 인·후두 내시경 검사상 편도나 후두에 부종이나 발적 등의 소견은 없었다. 혈액 검사상 백혈구 12.46 $\left(\times 10^{3} / \mu \mathrm{L}, 3 \sim 9.3\right)$, 분엽 호중구 79.5 $\left.\%, 40 \sim 70\right)$, 적혈구침강속 도 $72(\mathrm{~mm} / \mathrm{hr}, 0 \sim 30)$, C-반응단백 $10.07(\mathrm{mg} / \mathrm{dL}, 0 \sim 0.5)$ 로 염증 소견이 보였다. 경부 컴퓨터단층촬영에서 윤상연골 높 이부터 흥골 상부까지 후인두 공간이 두꺼워져 있었으며 저 밀도 음영을 보이고 있는 연조직염 소견이 보였다(Fig. 1A). 우측 갑상선 아래 부분에 $1.3 \times 2.1 \mathrm{~cm}$ 크기의 농양강(abscess cavity)이 기관 우측 옆에서 후인두 공간까지 침범하고 있었다 

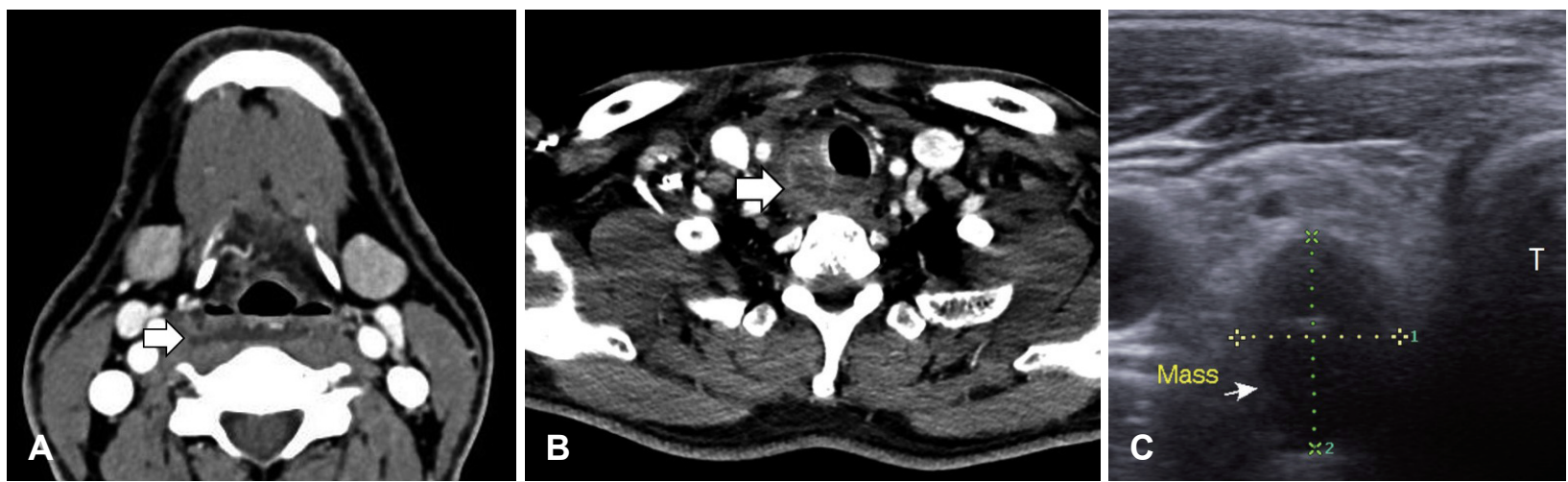

Fig. 1. Preoperative radiologic findings. Axial images of neck CT with enhancement showed low attenuated lesion at retropharyngeal and prevertebral space from C4 to T1 level (A, arrow). Axial image of neck CT with enhancement showed $1.3 \times 2.1 \mathrm{~cm}$ sized abscess cavity from right side of the trachea to prevertebral area $(B$, arrow). Neck ultrasonography showed $1.5 \times 2 \mathrm{~cm}$ sized hypoechoic, homogenous and round shaped mass at the right side of posterolateral tracheal wall (C, arrow).

(Fig. 1B). 초음파에서 우측 갑상선 아래 부분에 저음영의 균 질한 $1.5 \times 2 \mathrm{~cm}$ 크기의 구형 종괴가 관찰되었다(Fig. 1C). 임 상 소견들을 바탕으로 후인두 공간 심경부 감염을 먼저 의심 하였고, 감별 질환으로 새열 낭종이나 갑상선 또는 부갑상선 기원의 종물에 염증이 합병된 경우 등을 고려하였다. 원인 질 환에 대한 탐색적인 관점으로 농양에 대한 응급 절개 및 배 농 수술을 계획하였다.

전신마취하에서 수술은 쇄골에서 손가락 두 마디 위에 피 부 횡절개를 시행하여 접근하였다. 후인두의 상부에서는 색 깔이 투명하고 노란색의 장액성 액체가 나왔으며 탁한 농성 분비물의 소견은 없었다. 컴퓨터단층촬영에서 보였던 농양강 으로 추정되는 연조직이 갑상선 우엽의 바로 아래에서 기관 뒤를 감싸며 위치했다. 주위 조직들과 염증으로 인한 유착 소 견이 있었지만 갑상선의 아래 경과와는 비교적 잘 분리되어 갑상선 기원의 종물을 배제할 수 있었다. 농양강은 일반적으 로 피막이 없기 때문에 표면이 비교적 부드러우며 그 경계를 조작하면 잘 터지게 되는데, 갑상선과 분리할 때 이러한 소견 들이 없이 비교적 부드럽고, $2 \mathrm{~cm}$ 크기로 타원형의 붉은색을 띠는 피막을 가진 고형 종물 소견이 관찰되었다(Fig. 2).

기관 부위와 종물은 유착이 심해서 분리를 할 수 없었다. 종물과 농양강의 감별을 위해 피막을 절개하고 종물의 내부 를 관찰하였다. 농양 소견은 없었고, 소량의 염증성 삼출물이 있었고 종물의 대부분이 노란색의 연조직으로 가득 차 있었 다. 종물 내부에서 조직 검사를 시행하였다. 기관의 후측면은 반회후두신경의 주행 경로이고, 기관과 분리가 안 되는 큰 종 물이 위치하고 있어 신경 손상의 가능성이 높다고 판단하였 고, 향후 조직 검사 결과를 확인 후 필요 시 종물의 치료를 위한 2차 수술의 필요성을 보호자에게 설명하고 수술을 종료 하였다.

병리조직 검사 결과는 급성 화농성 감염 소견을 동반한 지

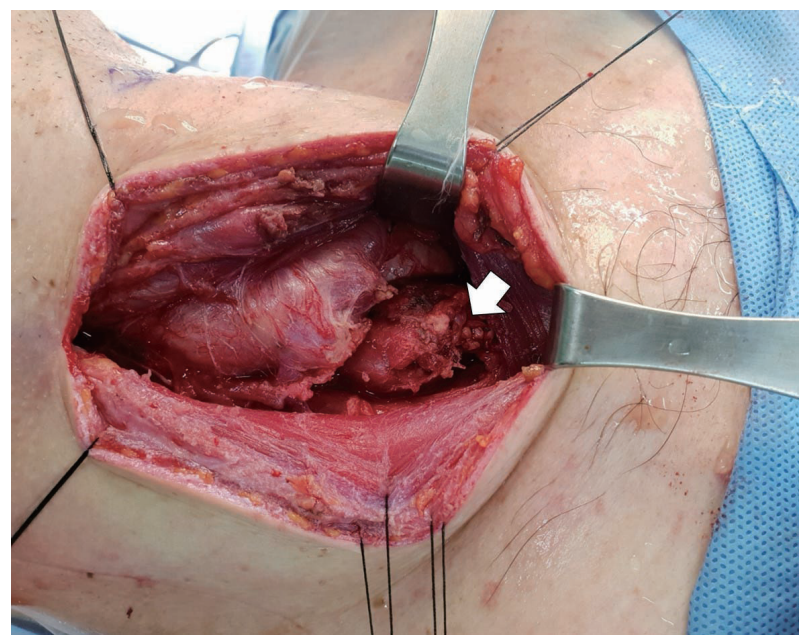

Fig. 2. Intraoperative photograph shows $2 \times 2 \mathrm{~cm}$ sized capsulated, soft, reddish mass located beneath the thyroid gland (arrow).

방 조직이 보였고, 결핵 중합효소 반응 검사에서 음성이었다. 술 후 3일째에 시행한 전산화단층촬영 검사상 기관 주위에 종물의 염증성 소견은 호전이 없었고 다른 후인두 병변들은 호전되었다(Fig. 3). 인후통, 발열 증상은 호전되었으며, 혈액 검사상 백혈구 $4.71\left(\times 10^{3} / \mu \mathrm{L}, 3 \sim 9.3\right)$, 분엽 호중구 $44.3(\%$, 40 70), 적혈구침강속도 $58(\mathrm{~mm} / \mathrm{hr}, 0 \sim 30), \mathrm{C}$-반응단백 0.56 $(\mathrm{mg} / \mathrm{dL}, 0 \sim 0.5)$ 으로 염증 수치의 호전 양상을 보였다. 다학 제적 회의 후 기관 낭종의 감염으로 인한 후인두 농양으로 진단되었다. 환자는 특별한 합병증 없이 수술 후 10 일 뒤 퇴 원하였다. 2 개월 뒤 외래에서 추적 검사로 시행한 전산화단 층촬영상 우측 기관 주위 농양강은 대부분 줄어들었으며, 농양이 있었던 기관의 우측 후방부에서 낭종이 발견되었다 (Fig. 4). 기관에서 낭종 확인을 위해 기관내시경을 시행하였 으나 연결 부위나 다른 특이 소견은 보이지 않았다. 기관 낭 종의 염증 소견이 호전되었고, 염증이 동반되는 경우가 드물 기 때문에 향후 재발 시 근치적 수술을 고려하기로 하였다. 


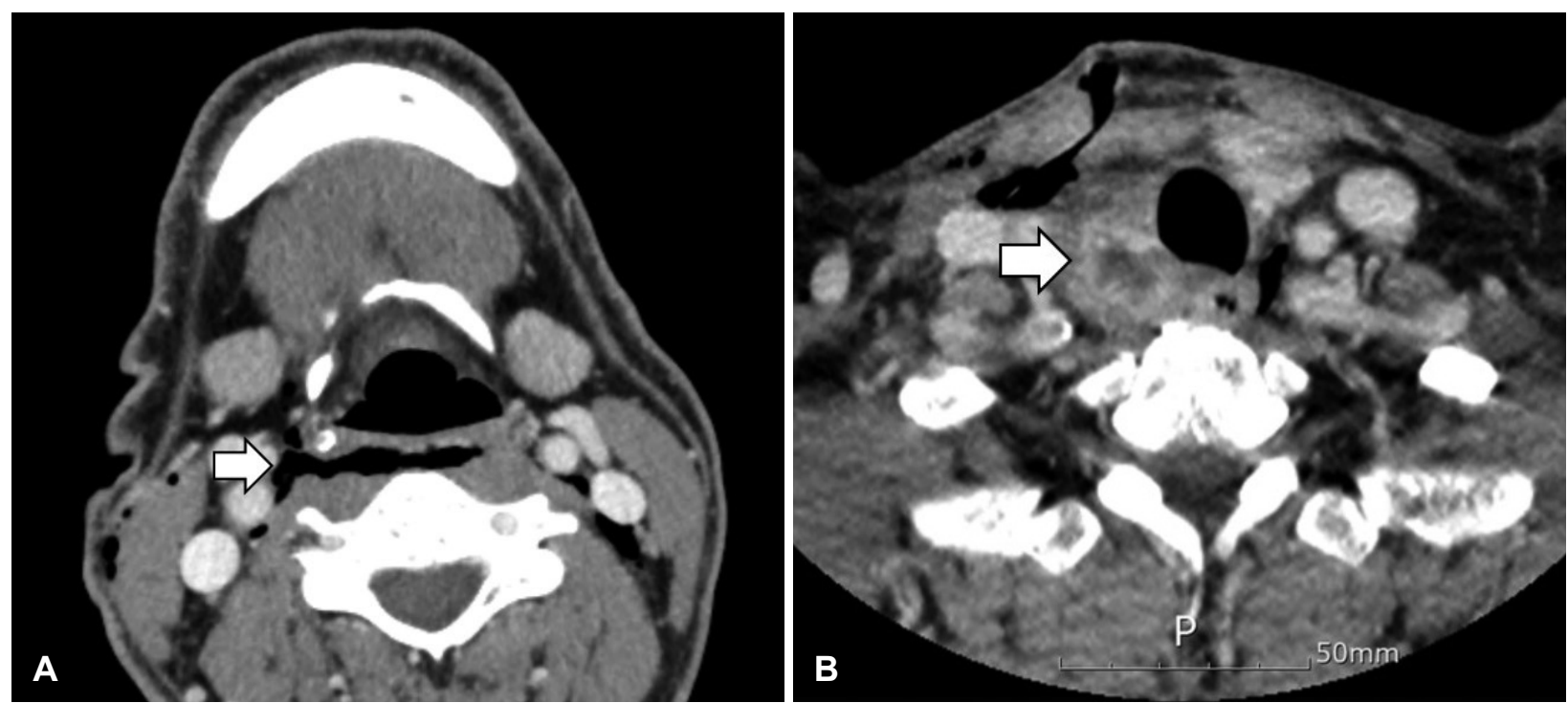

Fig. 3. Preoperative neck CT findings. Retropharyngeal abscess lesion was improved in axial image of post-treatment neck CT with enhancement ( $A$, arrow). There was no change in inflammation of abscess cavity in the right side the trachea (B, arrow).
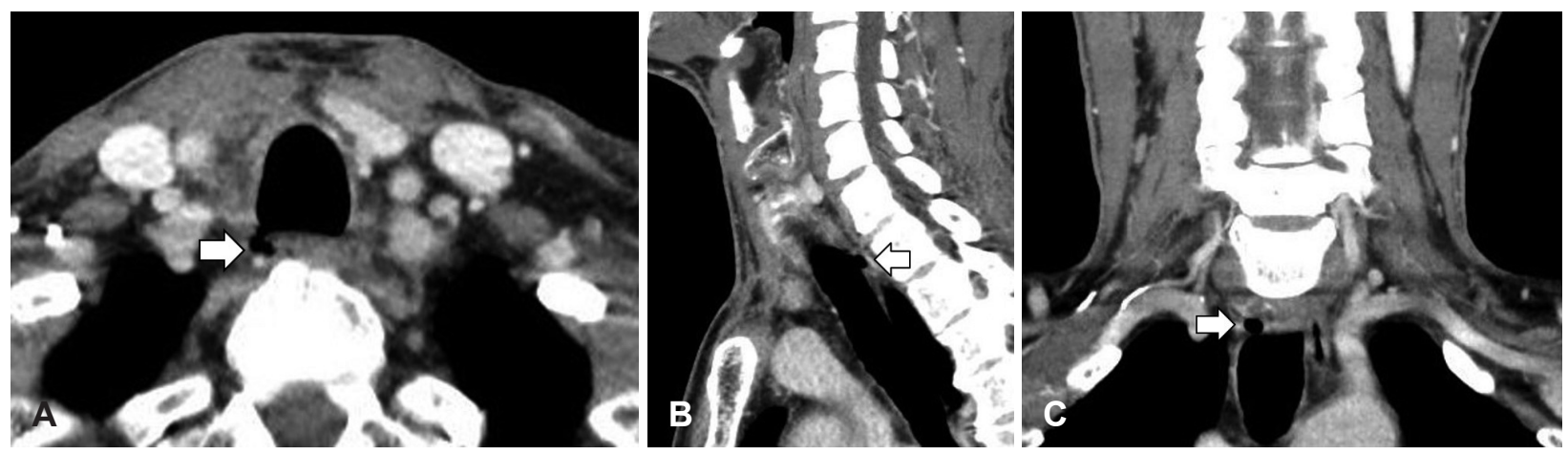

Fig. 4. Postoperative neck CT findings 2 months after surgery. An air filled paratracheal cyst (arrows) was located at the right side of the trachea in the axial view $(A)$, sagittal view $(B)$ and coronal view $(C)$.

수술 후 1년간 외래 경과 관찰 중 염증의 재발 소견은 없고, 영상 검사에서 낭종의 변화 소견은 없었다.

\section{고 찰}

기관 낭종은 기관 게실, 후두 게실, Zenker 게실 등과 같은 섬모성 상피로 둘러싸여 있는 낭종성 질환 등에 의해서 나타 날 수 있으며 선천적인지 후천적인지는 아직 알려져 있지 않 다. 몇몇의 연구에서는 대다수의 기관 낭종은 기관 게실에서 호발한다고 알려져 있다. ${ }^{1)}$ 기관 게실은 기관의 우측 후벽에 위 치하는 경우가 약 $98 \%$ 를 차지한다. 이는 식도와 대동맥궁이 기관의 좌측에 위치해 있고, 기관의 연골 중 후벽이 약하기 때문이라고 알려져 있다.,5) 기관 게실은 선천적인 병변과 후 천적인 병변으로 나눌 수 있다. 선천적 기관 게실은 외상, 장 기간의 기관절개술 상태가 원인이 될 수 있으며, 반복적인 기 관 점액 분비선의 감염, 만성적인 기침이 게실 생성의 부가적

\section{요인으로 밝혀져 있다. ${ }^{6,7}$}

대다수의 기관 낭종은 증상이 없고 우연히 발견된다. 드물게 호흡기계의 분비물이 낭종 내에 쌓이는 경우 기관 낭종이 감염 되어 호흡기 증상을 나타낼 수 있다. 그리고 이러한 감염이 자 주 발생하고, 만성적으로 발생한다면 폐결핵이나 종양처럼 보여질 수도 있으며, 크기가 커질 경우 종괴에 의한 증상으로 호흡곤란, 연하곤란, 애성 등이 나타날 수 있다. ${ }^{89}$

기관 낭종을 진단하기 위해 초음파, 컴퓨터단층촬영, 기관 지 내시경 등이 사용된다. 초음파에서 기관 낭종은 보통 반향 허상(reverberation artifacts)이 동반된 저음영의 종괴 소견 을 보인다. ${ }^{3)}$ 기관 주위 종괴 소견이 보일 시 결핵성 림프절염 및 전이성 림프절염 등을 배제하기 위해 수술 전 생검을 먼저 고려해야 한다. 컴퓨터단층촬영은 기관 낭종의 크기와 위치, 형상, 그리고 기관과 연결된 부위 등을 파악하기에 가장 유용 하며 대부분 흥추 1 번에서 2 번 높이에서 우측 후하방으로 나 타난다. ${ }^{5)}$ 본 증례에서도 가장 나중에 시행한 컴퓨터단층촬영 
에서 기관 낭종은 흉추 1 번 높이에서 발견되었다. 기관 낭종 은 보통 크기가 작기 때문에 선행 정보가 없는 경우에는, 기 관내시경으로 연결된 부위를 놓치는 경우가 있을 수 있다. ${ }^{10)}$ 또한 Zenker 게실과 같은 기관 낭종의 식도 연결을 확인하기 위해서는 식도내시경이나 식도 조영술이 필요할 수도 있다. ${ }^{11)}$

기관 낭종의 치료는 증상이 없다면 대부분의 경우는 경과 를 지켜보며, 지속적인 감염이 있으면 우선 항생제 치료를 한 다. 치료에도 불구하고 증상이 조절되지 않거나, 크기가 커져 다른 구조물들을 압박하는 증상이 발생하거나 재발할 경우 수술적 치료를 고려할 수 있다. ${ }^{11)}$ 본 증례와 같이 경부에 발생 한 경우 경부접근법을 이용한 완전 절제를 시행하여야 재발 을 줄일 수 있다. 감염에 의한 염증이 있었다면 주변 조직과 유착이 보이며, 이 같은 경우 반회후두신경과 경동맥과 같은 중요 구조물에 유의하여 수술을 진행해야 한다. ${ }^{12}$ 기관 주위 낭종을 세절편 컴퓨터단층촬영으로 촬영 시 기관과 교통이 있는 경우가 35 55\%를 차지한다. 낭종이 기관과 교통하는 경 우에는 낭종을 제거하고 기관과의 교통 부위를 1차 봉합하 여야 수술 후 누공이 발생하지 않는다. ${ }^{11)}$

저자들의 증례는 증상 없이 지내던 환자가 기관 낭종이 서 서히 커지다가 급성 염증이 발생한 것으로, 기관 낭종이 위치 한 기관지 후면의 후인두 공간으로 염증이 파급된 것으로 추 정된다. 응급 배농 수술을 할 때 그 당시에는 원인을 정확히 알 수 없었지만, 무리하게 종양처럼 커진 기관 낭종을 제거하 지 않고 조직 검사 후 2차 수술을 계획함으로써 특별한 부작 용 없이 회복할 수 있었다. 후인두 농양이 발생하고 우측 기 관 주위로 종물이나 농양강이 동반되는 경우는 드물지만 기 관 낭종의 감염 가능성을 고려하면서 신중한 수술적 접근을 고려해야 한다.

\section{Acknowledgments}

None.

\section{Author Contribution}

Conceptualization: Dong Kun Lee. Investigation: Eun Soo Lee. Supervision: Heon Soo Park. Visualization: Sang Hyeon Kim. Writing — original draft: Eun Soo Lee. Writing — review \& editing: Dong Kun Lee.

\section{ORCID}

Dong Kun Lee https://orcid.org/0000-0002-7296-1420

\section{REFERENCES}

1) Goo JM, Im JG, Ahn JM, Moon WK, Chung JW, Park JH, et al. Right paratracheal air cysts in the thoracic inlet: Clinical and radiologic significance. AJR Am J Roentgenol 1999;173(1):65-70.

2) Tanrivermis Sayit A, Elmali M, Saglam D, Celenk C. The diseases of airway-tracheal diverticulum: A review of the literature. J Thorac Dis 2016;8(10):E1163-7.

3) Kim HJ, Jou SS, Kim YT, Han JK. Infected paratracheal air cyst: A case report. J Korean Soc Radiol 2016;75(1):68-72.

4) Kim HK, Lee JI, Jang HW, Bae SY, Lee JH, Kim YS, et al. Characteristics of Killian-Jamieson diverticula mimicking a thyroid nodule. Head Neck 2012;34(4):599-603.

5) Sato T, Sasaki Y, Yamasaki M, Aragaki M, Mae S, Irie T, et al. A right paratracheal air cyst caused by tracheal diverticula. Intern Med 2010;49(4):315-9.

6) Yazkan R, Ozpolat B, Firat H. Tracheocele; a case of rare clinical entity. Tuberk Toraks 2008;56(3):315-8.

7) Amaral CB, Silva S, Feijó S. Infected tracheal diverticulum: A rare association with alpha-1 antitrypsin deficiency. J Bras Pneumol 2014;40(6):669-72.

8) Rhee YJ, Han SJ, Chong YY, Cho HJ, Kang SK, Lee CS, et al. Voice change due to paratracheal air cysts. Korean J Thorac Cardiovasc Surg 2016;49(4):313-6.

9) Chaudhry I, Mutairi H, Hassan E, Afzal M, Khurshid I. Tracheal diverticulum: A rare cause of hoarseness of the voice. Ann Thorac Surg 2014;97(2):e29-31.

10) Moz U, Gamba P, Pignatelli U, D’Addazio G, Zorzi F, Fiaccavento $S$, et al. Bronchogenic cysts of the neck: A rare localization and review of the literature. Acta Otorhinolaryngol Ital 2009;29(1):36-40.

11) Bae K, Jeon KN, Park MJ, Lee SJ, Kim HC, Cha SI, et al. Overlooked diagnosis of infected paratracheal air cysts in patients with respiratory symptoms: Case report. Medicine (Baltimore) 2017; 96(29):e7536.

12) Kang SH, Jin SM, Kim HK, Yoon TM. Cervical bronchogenic cyst mimicking thyroid cyst. Int J Thyroidol 2017;10(2):118-22. 